\title{
CHARACTERIZATION OF CuO-NANOADDITIVE BLENDED ENGINE OIL
}

\section{Bishow Raj Subedi, Hira Mani Trital and Armila Rajbhandari (Nyachhyon)}

Journal of Institute of Science and Technology

Volume 22, Issue 1, July 2017

ISSN: 2469-9062 (print), 2467-9240 (e)

\section{Editors:}

Prof. Dr. Kumar Sapkota

Prof. Dr. Armila Rajbhandari

Assoc. Prof. Dr. Gopi Chandra Kaphle

JIST, 22 (1): 152-158 (2017)

Published by:

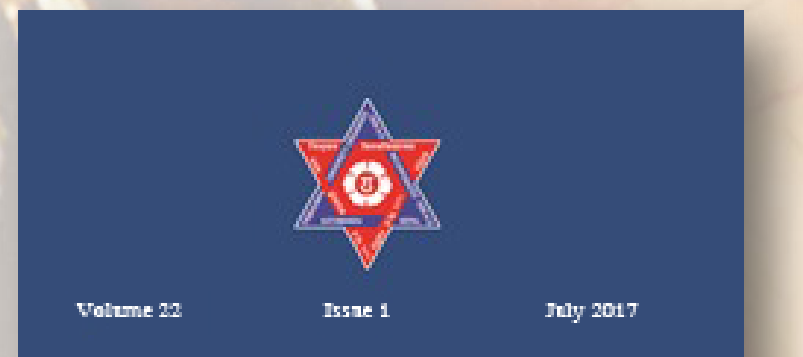

JOURNAL OF INSTITUTE OF

SCIENCE AND TECHNOLOGY

Institute of Science and Technology

Tribhuvan University

Kirtipur, Kathmandu, Nepal 


\title{
CHARACTERIZATION OF CuO-NANOADDITIVE BLENDED ENGINE OIL
}

\author{
Bishow Raj Subedi ${ }^{1}$, Hira Mani Trital ${ }^{2}$ and Armila Rajbhandari (Nyachhyon), ${ }^{1, *}$ \\ ${ }^{1}$ Central Department of Chemistry, Tribhuvan University, Kirtipur, Nepal \\ ${ }^{2}$ Nepal Lube Oil Ltd., Amlekhgunj, Bara, Nepal \\ *Corresponding E-mail: armila3@yahoo.com
}

\begin{abstract}
Copper oxide $(\mathrm{CuO})$ nanoadditives were successfully synthesized in laboratory by precipitation technique. $\mathrm{X}$-ray diffraction spectroscopy (XRD) showed the crystalline nature of $\mathrm{CuO}$ with the average crystal size of $10 \mathrm{~nm}$. The prepared $\mathrm{CuO}$ has been blended with engine oil. Thus prepared modified engine oil showed good kinematic viscosity $158 \mathrm{cSt}$ and $19.06 \mathrm{cSt}$ at $40^{\circ} \mathrm{C}$ and $100^{\circ} \mathrm{C}$ respectively. The viscosity index was also found to be improved to 122 . Similarly, the pour point was also found to be considerably decreased to $27^{\circ} \mathrm{C}$ which is due to presence of $\mathrm{CuO}$ that acts as good pour point depressant. The flash point of modified engine oil reached to $225^{\circ} \mathrm{C}$. In addition, modified engine oil was found to be reluctant towards water and it does not contain noticeable amount of water and found to be noncorrosive in nature having copper strip corrosion rating $1 \mathrm{~b}$ according to ASTM D-130 method. Results revealed that the physio-chemical parameters of engine oil could be improved by the addition of $\mathrm{CuO}$ nanoadditive.
\end{abstract}

Keywords: CuO, Metal oxide, Engine oil 20W-50, Modified engine oil, Kinematic Viscosity, Viscosity Index, Flash Point, Pour Point.

\section{INTRODUCTION}

The wear, tear and corrosion of engine usually occur due to frictional resistance produced between the sliding surfaces during motion. Thus the loss of engine parts is usually observed. To reduce such friction, lubricants are normally used in engine as it is relatively inexpensive, thermally stable and also act as good coolant for machinery parts. Moreover, they also provide an appropriate range of viscosities. Lubricant that is used in engine is called here as engine oil and is graded according to SAE (Society of Automotive Engineers). SAE $15 \mathrm{~W}-50$, SAE $20 \mathrm{~W}-50$, SAE $5 \mathrm{~W}-40$, SAE $10 \mathrm{~W}-60$ are the names of some engine oils given according to their grade (www.viscopedia.com). Additives are synthetic macro chemical molecules used to improve different lube parameters and are normally mixed with engine oils to prevent engine from excessive friction (Ahmed et al., 2014). Recently, the macro sized additives have been replaced by nano-sized additives which have been reported in literatures. These are nano-sized $\mathrm{Cu}, \mathrm{CuO}, \mathrm{TiO}_{2}$, $\mathrm{CeO}_{2}, \mathrm{ZnO}, \mathrm{Al}_{2} \mathrm{O}_{3}, \mathrm{SiC}$, nano-diamond, graphite, molybdenum disulphide, tungsten disulphide etc (Zhou et al., 1999; Zhou et al., 2001; Bahadur et al., 2005; Barttez et al., 2006; Thottackkad et al., 2014; Bhaumik et al., 2014; Pisal et al., 2014; Pathak et al., 2015). In order to stabilize the nano-sized particles or to protect the growth of particle size or to overcome the spontaneous coalescence, surfactants have been used along with nanoadditives. Polyethylene glycol, lauryl sodium sulfate, triton $\mathrm{X}-100$ etc are the surfactants generally used for the surface modification of the prepared nano-sized additive (Zhou et al., 1999; Zhou et al., 2001; Bahadur et al., 2005; Barttez et al., 2006; Thottackkad et al., 2014; Bhaumik et al., 2014; Pisal et al., 2014; Pathak et al., 2015). In this study, we try to prepare $\mathrm{CuO}$ nanoadditives for engine oil and lauryl sodium sulfate as surfactant.

\section{MATERIALS AND METHODS}

Copper nitrate dehydrate and sodium hydroxide was obtained from Qualigens, Fisher scientific Company, India. Distilled water was used throughout the experiment.

Synthesis of copper oxide nanoadditive $(\mathrm{CuO})$ :

Solution of $0.1 \mathrm{M}$ copper nitrate $\left(\mathrm{CuNO}_{3} \cdot 2 \mathrm{H}_{2} \mathrm{O}\right)$ was added from the burette in drop to $0.1 \mathrm{M} \mathrm{NaOH}$ 
solution containing lauryl sodium sulfate (SDS) as capping agent in a beaker. During the addition, stirring was done continuously with the help of magnetic stirrer. Then metal hydroxide was obtained which was filtered and washed with dehydrated ethyl alcohol and distilled water alternatively for several times. Finally, the washed precipitate was calcinated at $500^{\circ} \mathrm{C}$ for 6 hours in a muffle furnace (Phiwdang et al., 2013; Veerendra et al., 2014).

\section{Characterization of $\mathrm{CuO}$ :}

The crystalline structure and particle size of the metal oxide were studied by X-ray diffractometer using $1.5406^{\circ} \mathrm{A}$ wavelength radiations. The particle size of metal oxide was calculated by using Scherrer's equation (Veerendra et al., 2014).

$$
\mathrm{D}=\frac{\mathrm{K} \lambda}{\beta \cos \theta}
$$

Where, $\mathrm{K}$ is the shape factor for spherical particles with value equal to 0.9 . Similarly, $\lambda$ is the wave length of $X$-ray radiation is equal to $0.15406 \mathrm{~nm}$ whereas $\beta$ is the full width at half maximum and $\theta$ is Bragg's angle. Here D indicates the average particles size. The fourier transform infrared (FTIR) spectroscopy of copper oxide $(\mathrm{CuO})$ was recorded in an FTIR spectrometer (Model: IRPrestige-21, SHIMADZU) within the range of $250-4000 \mathrm{~cm}^{-1}$.

\section{Preparation of modified engine oil (MEO):}

The modified engine oil has been prepared by mixing $1.78 \mathrm{~g}$ of surface modified $\mathrm{CuO}$ nanoparticle with 1 liter of engine oil maintaining $0.2 \%$ weight by weight. Then it was stirred for 6 hours with $2000 \mathrm{rpm}$ by using elite motor so that the metal oxide gets well dispersed without any settlement (Etteefaghi et al., 2013; Bhumik et al., 2015). Figure 1 shows the preparation of modified engine oil by using elite motor.

\section{Stability test of MEO:}

The prepared modified engine oil $(0.2 \% \mathrm{wt} / \mathrm{wt})$ was kept in stationary condition in the completely transparent glassy vessel for a week.

Study of different physio-chemical parameters of engine oil (EO) and modified engine oil (MEO):

The physio-chemical parameters and methods utilized for the study are given in table 1 .

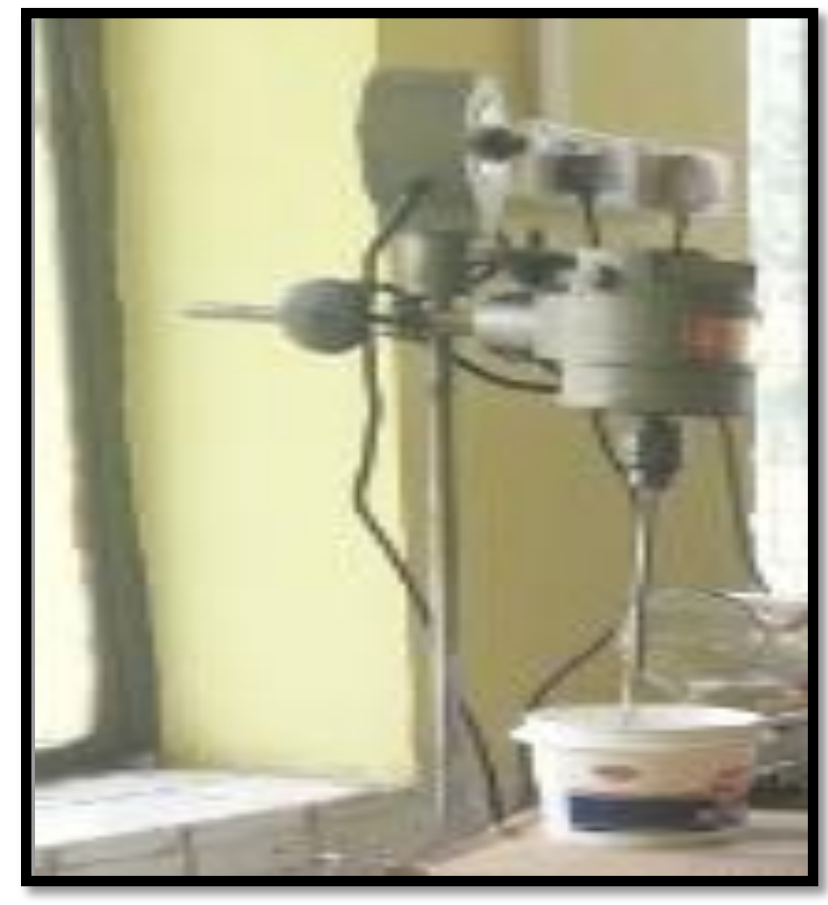

Fig.1. Preparation of modified engine oil (MEO) by mixing engine oil and additive using elite motor.

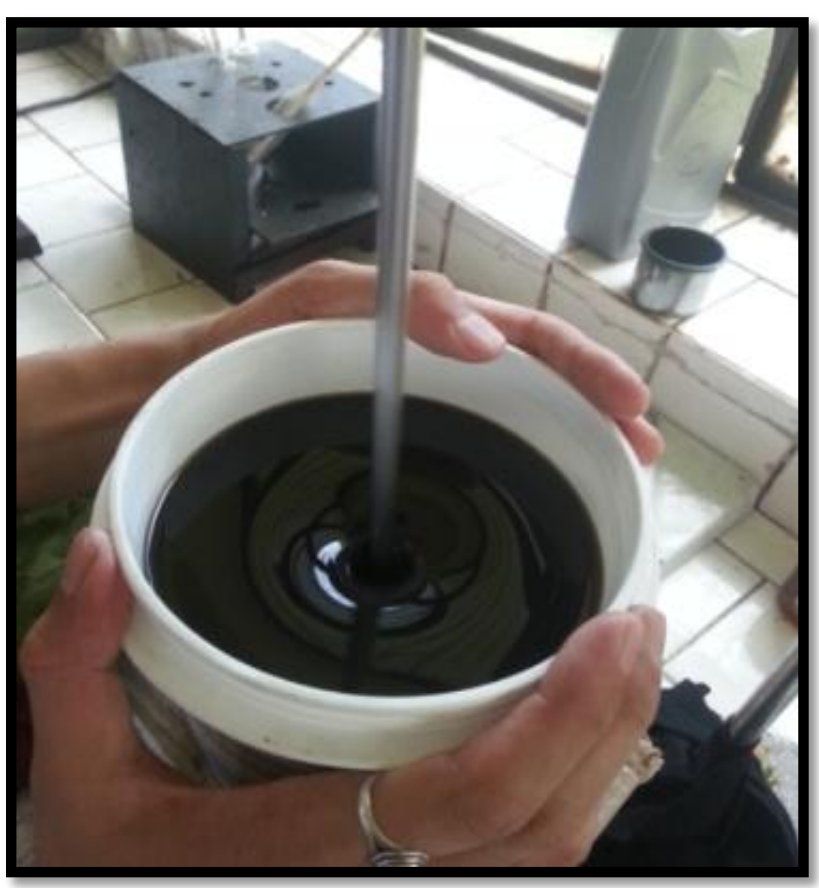

Fig. 2. The modified engine oil. 
Table 1. ASTM Test methods involved for the study of physio-chemical parameter of engine oil (EO) and modified engine oil (MEO) (Annual book of ASTM, 1985):

\begin{tabular}{|l|l|l|}
\hline S.N & \multicolumn{1}{|c|}{ Test Parameters } & ASTM method \\
\hline 1 & Kinematic Viscosity at $40{ }^{\circ} \mathrm{C} \mathrm{cSt}$ & D 445 \\
\hline 2 & Kinematic Viscosity at $100{ }^{\circ} \mathrm{C} \mathrm{cSt}$ & D 445 \\
\hline 3 & Viscosity Index & D 2770 \\
\hline 4 & Pour Point, ${ }^{\circ} \mathrm{C}$ & D 97 \\
\hline 5 & Flash Point, ${ }^{\circ} \mathrm{C}$ & D 92 \\
\hline 6 & Corrosion Test (Copper Strip Test) & D 130 \\
\hline 7 & Moisture Content (Crackle Test) & - \\
\hline 8 & pH & - \\
\hline
\end{tabular}

\section{RESULTS AND DISCUSSION}

The prepared copper oxide nanoparticle is shown in figure 3. The prepared material was found to be black in colour and was in powder form.

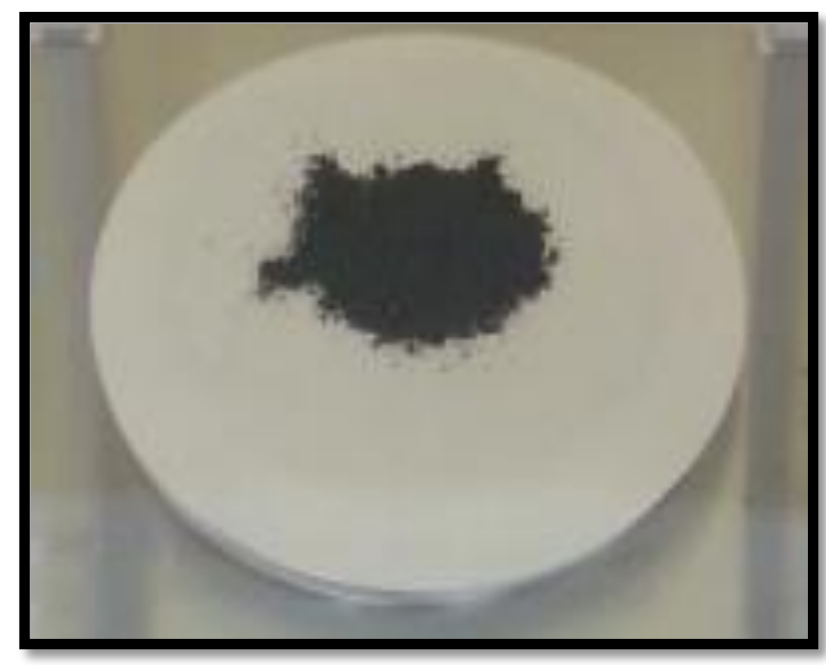

Fig. 3. $\mathrm{CuO}$ nanoparticles.

\section{Characterization of $\mathrm{CuO}$ additive: \\ $\mathrm{X}$-ray diffraction studies}

The XRD pattern of as prepared $\mathrm{CuO}$ is shown in figure 4.The diffraction peaks are well defined and are in good agreement with JCPDS card No 895899 for $\mathrm{CuO}$. In the figure, one can observe sharp diffraction peaks at (20) 35, 39, 49, 53, 58, 62, 66, $68,72 \& 75$. The sharp diffraction peaks is the indication of crystalline nature of the material.

The average crystalline size of the copper oxide was found to be $10 \mathrm{~nm}$. The XRD pattern and crystalline size are quite analogous with reported value (Bhumik et al., 2015). The $\mathrm{CuO}$ nano structures that is nanotubes are also reported for various applications including nanoadditive properties (Paudel et al., 2016).

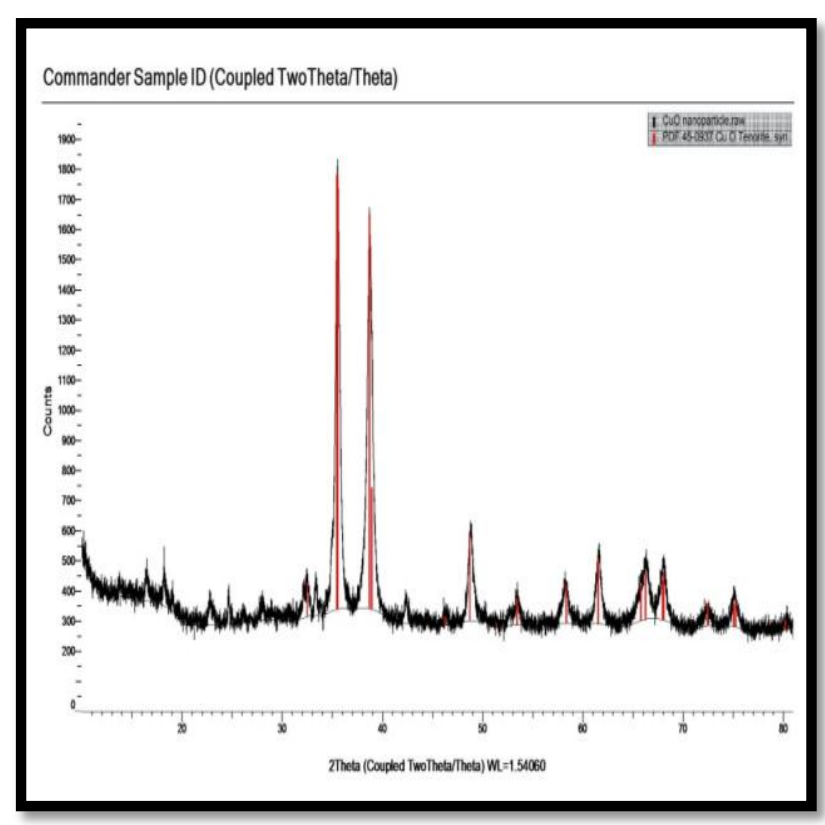

Fig. 4. XRD pattern of $\mathrm{CuO}$.

\section{FT-IR studies:}

The FT-IR spectrum obtained is shown in figure 5 . The weak and broad bands around 3387- $3600 \mathrm{~cm}^{-1}$ and $1606 \mathrm{~cm}^{-1}$ was observed which indicates the stretching band of hydroxyl groups. Similarly, weak vibration band at $1600 \mathrm{~cm}^{-1}$ could be seen which indicates the presence of little water absorbed on the surface of metal oxide. A peak around the $1111 \mathrm{~cm}^{-1}$ was found which broadcast the stretching band of $\mathrm{C}-\mathrm{H}$ vibration. It can also be observed that the $\mathrm{Cu}-\mathrm{O}$ stretch band at around 600 
$\mathrm{cm}^{-1}$. Peaks are displayed more clearly in inset picture. These bands obtained from FT-IR were in close agreement with bands reported in the literature (Bhumik et al., 2015).

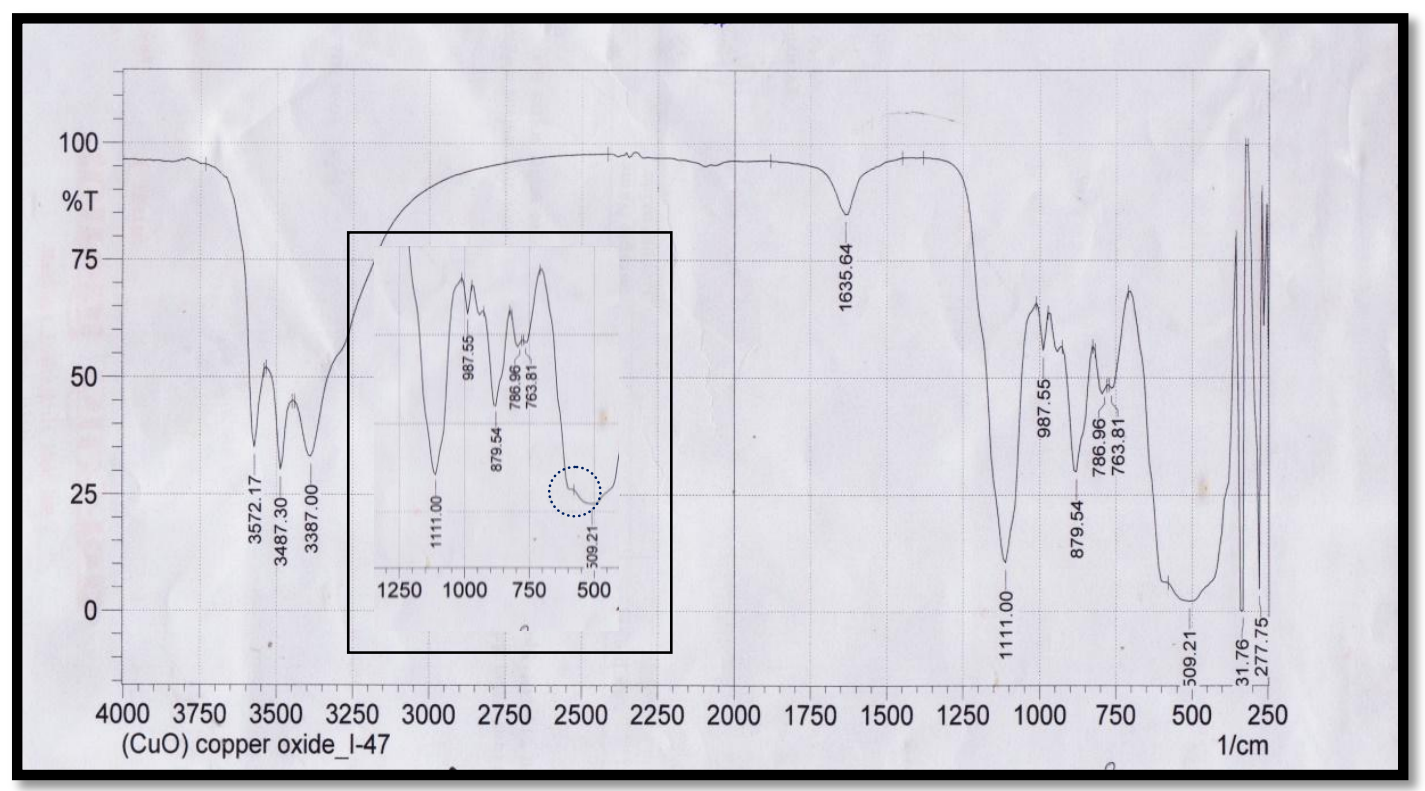

Fig.5. IR-Spectra of CuO. Most useful peaks are displayed in inset picture.

\section{Stability of Modified Engine Oil (MEO):}

The modified engine oil was observed after keeping undisturbed for one week. No precipitation in the bottom of vessel was observed. It showed the stability of engine oil along with additive.

Study of physiochemical parameters of engine oil (EO) and modified engine oil (MEO):

\section{Kinematic Viscosity:}

The kinematic viscosity of engine oil and modified engine oil at $40^{\circ} \mathrm{C}$ and $100{ }^{\circ} \mathrm{C}$ was obtained and is given in table 2 . The results were then compared and are presented in the bar diagram (Figure 6). It is obvious that the kinematic viscosity of both oils were found to decrease with rise in temperature from $40^{\circ} \mathrm{C}$ to $100^{\circ} \mathrm{C}$. The shrinkage might be due to the weakening of inter-particle and intermolecular adhesion forces. Besides, the kinematic viscosity in case of modified engine oil was found to be slightly higher than that of parent engine oil. This may be due to presence of additives. It may cause slight increase in the internal shear stress of the engine oil.

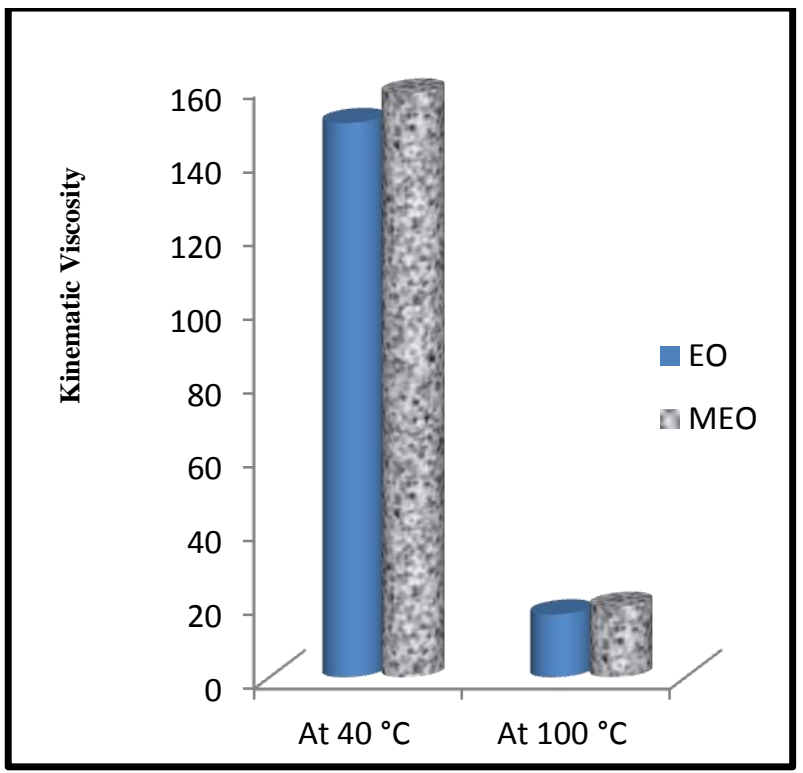

Fig. 6. A bar diagram showing the kinematic viscosity of engine oil (EO) and modified engine oil (MEO).

Table 2. Kinematic Viscosity of engine oil (EO) and modified engine oil (MEO) at $40^{\circ} \mathrm{C}$ and $100^{\circ} \mathrm{C}$.

\begin{tabular}{|l|l|l|l|}
\hline S.N. & Sample & K.V. at $40^{\circ} \mathbf{C}(\mathbf{c S t})$ & K.V. at $\mathbf{1 0 0}{ }^{\circ} \mathbf{C}(\mathbf{c S t})$ \\
\hline 1 & EO & 150 & 17.00 \\
\hline 2 & MEO & 158.22 & 19.06 \\
\hline
\end{tabular}




\section{Viscosity index:}

On the basis of ASTM viscosity index table, the viscosity index of engine oil (EO) and modified engine oil (MEO) were calculated and were found to be 122 and 137 respectively. The obtained result is expressed in bar graph (Figure 7) which clearly depicts the higher viscosity index of modified engine oil.

Table 3. Viscosity index of engine oil (EO) and modified engine oil (MEO).

\begin{tabular}{|l|l|l|}
\hline S.N. & Sample & Viscosity Index \\
\hline 1 & EO & 122 \\
\hline 2 & MEO & 137 \\
\hline
\end{tabular}

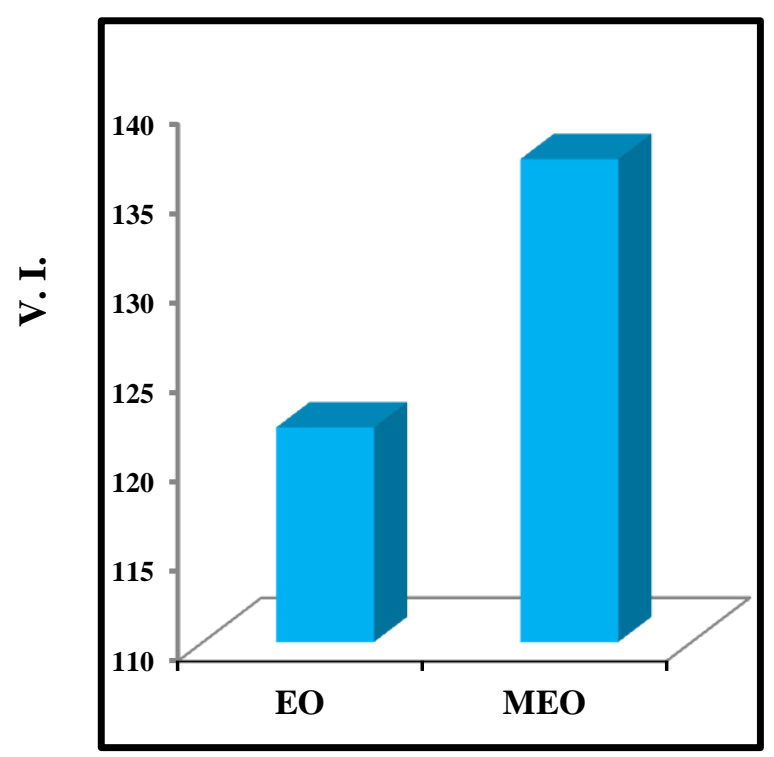

Fig.7. A bar diagram showing the Viscosity Index (V. I.) of engine oil (EO) and modified engine oil (MEO).

\section{Pour Point:}

Pour point of engine oil (EO) and modified engine oil (MEO) is given in table 4. The change of pour point of modified engine oil (MEO) could be seen in figure 8 . The pour point is noticeably lower in modified engine oil (MEO) which is equal to $-27^{\circ} \mathrm{C}$. This value is $6^{\circ} \mathrm{C}$ less than pour point of engine oil (EO). It is the positive indication of good property of lubricant. Hence, it can be unquestionable that the modified engine oil can be used in vehicles and machineries even in the extreme cold environment condition.
Table 4. Pour point of engine oil (EO) and modified engine oil (MEO).

\begin{tabular}{|l|l|l|}
\hline S.N. & Sample & Pour point $\left({ }^{\circ} \mathrm{C}\right)$ \\
\hline 1 & EO & -21 \\
\hline 2 & MEO & -27 \\
\hline
\end{tabular}

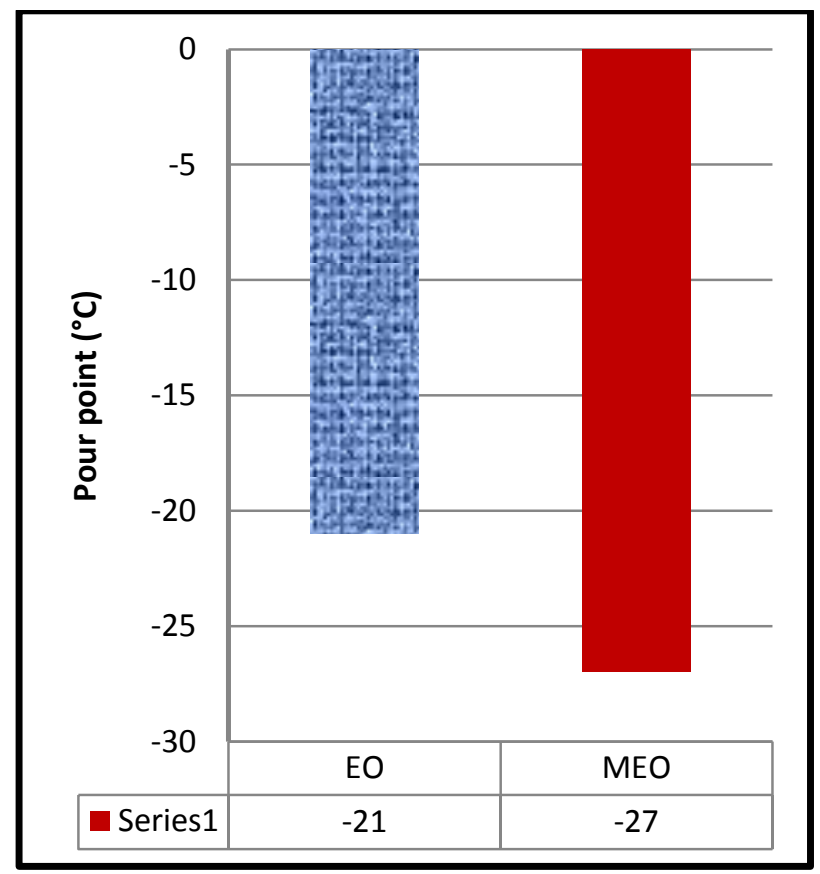

Fig.8. A bar diagram showing the of pour point of engine oil (EO) and modified engine oil (MEO).

\section{Flash Point:}

The flash point of engine oil (EO) and modified engine oil (MEO) are given in table 5. Here, the flash point of engine oil (EO) and modified engine oil (MEO) was found to be $213^{\circ} \mathrm{C}$ and $225{ }^{\circ} \mathrm{C}$ respectively. The changes of flash point of engine oil with addition of $0.2 \%$ copper oxide $(\mathrm{CuO})$ nanoparticles as additive could be clearly seen (Figure 9). Here flash point of modified engine oil is increased by $5.63 \%$ of engine oil. It may be due to rise in thermal conductivity by addition of copper oxide nanoparticles as additive. It can be said that it helps the oil to resist against ignition. In addition to this, extra material or additive which was added is nonvolatile substance leads to fewer amounts of vapors during flash point examination. It signifies that the modified engine oil can show its lubricating property up to $225^{\circ} \mathrm{C}$ without being ignited. It means that the prepared engine oil can work as good oil even at higher temperature condition of different engines. 
Table 5. Flash point of engine oil (EO) and modified engine oil (MEO).

\begin{tabular}{|l|l|l|}
\hline S.N. & Sample & Flash point $\left({ }^{\circ} \mathrm{C}\right)$ \\
\hline 1 & EO & 213 \\
\hline 2 & MEO & 225 \\
\hline
\end{tabular}

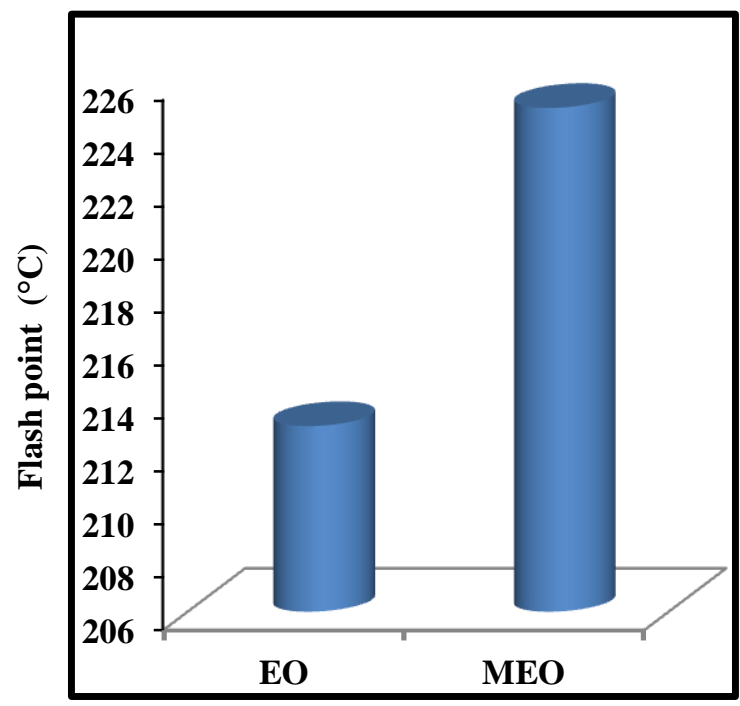

Fig.9. A bar diagram showing the flash point of engine oil (EO) and modified engine oil (MEO).

\section{Corrosion Test (Copper Strip Test):}

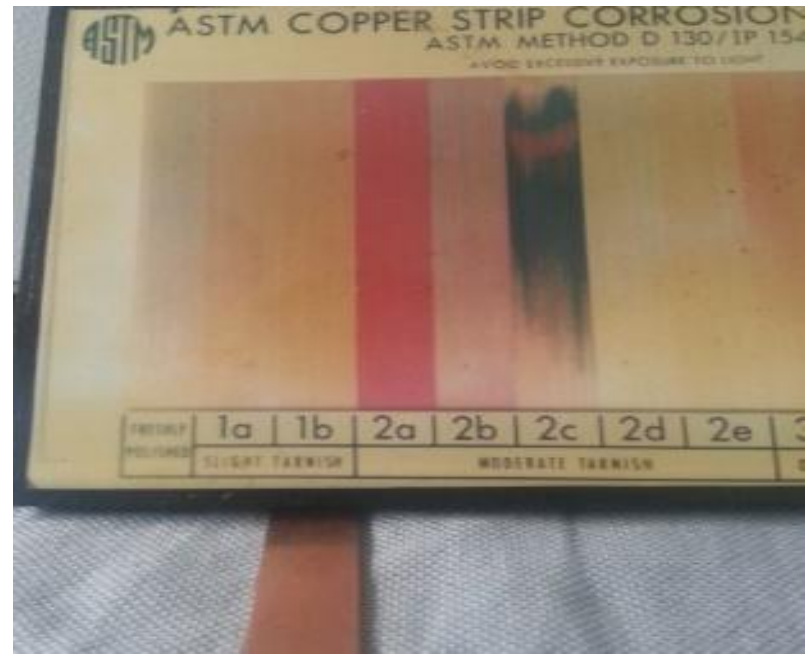

Fig.10. Copper strip corrosion tests of MEO.

The copper strip corrosion test is shown in figure 19 and results are presented in table 7 . The results exposed that the corrosiveness of engine oil and modified engine oil both reached a rating of $1 \mathrm{~b}$ according to ASTM standard D 130-12.
Table 7. Copper strip corrosion tests of engine oil (EO) and modified engine oil (MEO).

\begin{tabular}{|l|l|l|}
\hline S.N. & Sample & $\begin{array}{l}\text { Copper strip } \\
\text { corrosion, rating }\end{array}$ \\
\hline 1 & EO & $1 \mathrm{~b}$ \\
\hline 2 & MEO & $1 \mathrm{~b}$ \\
\hline
\end{tabular}

\section{Moisture Content Test (Crackle Test):}

This test was carried to confirm the moisture in engine oil. During the course of test, water vapour was not present on the mouth of the test tube. Also during heating process, no any crackle sound was noticed. It means that the modified engine oil was devoid of appreciable quantity of water.

pH Measurement:

The $\mathrm{pH}$ of the modified engine oil was found to be 6.42. This indicates the oil is neutral and it doesn't cause any corrosion in machinery parts or engines.

\section{CONCLUSION}

From the study, it has been concluded that:

1. Copper oxide $(\mathrm{CuO})$ can be synthesized by precipitation method.

2. XRD pattern of as prepared $\mathrm{CuO}$ showed the crystalline nature of the material with average grain size of $10 \mathrm{~nm}$.

3. FT-IR spectrum showed the presence of $\mathrm{Cu}-\mathrm{O}$ band at around $600 \mathrm{~cm}^{-1}$.

4. The absence of precipitation in the bottom of container indicates the stability of $\mathrm{CuO}$ in engine oil.

5. Kinematic Viscosity was found greater in modified engine oil (MEO) than engine oil (EO).

6. Viscosity index was found to be increased from 122 for EO to 137 in MEO which indicates the stability of MEO towards temperature.

7. Pour point of MEO was found to be $-27{ }^{\circ} \mathrm{C}$ which signifies its utility even in the extreme cold condition.

8. Flash point of modified engine oil (MEO) was found to be increased from $213^{\circ} \mathrm{C}$ to $225{ }^{\circ} \mathrm{C}$. $\mathrm{So}, \mathrm{CuO}$ can be used as flash point enhancer.

9. The corrosion rating $1 \mathrm{~b}$ was assigned for EO and MEO which indicates that both oil do not corrode machinery devices.

10. The noted $\mathrm{pH}$ around the neutral range i.e. 6.42 indicates the modified engine oil is not harmful for machinery devices. 
11. All the physiochemical parameters of the modified engine oil (MEO) were found to be improved than in parent engine oil (EO) by the addition of $\mathrm{CuO}$ nanoparticles as additive.

\section{ACKNOWLEDGEMENTS}

One of the author Bishwo Raj Subedi is thankful to University Grants Commission (UGC) Nepal for providing thesis support grant and Nepal Lube Oil for providing all laboratory facilities.

\section{REFERENCES}

Ahmed, N. S.; Nassar, A. M.; Abdel, Y. K.; Abdel, Y.; El-Shazyl, R. (2014). Preparation, characterization and evaluation of some metallic lube oil additives, Journal of Applied Chemistry, 7 (12): 56-67.

Annual Book of American Soceity for Testing and Materials (ASTM) (1985). 5 (2).

Ashok, C. H.; Rao, K. V. and Chakra, C. H. S. (2016). Facile synthesis and characterization of $\mathrm{ZnO} / \mathrm{CuO}$ nanocomposite for humidity sensor application, Journal of Advanced Chemical Science, 2: 223-226.

Bahadur, S. and Sunkara, C. (2005). Effect of transfer film structure, composition and bonding on the tribological behavior of polyphenylene sulfide filled with nano particles of $\mathrm{TiO}_{2}, \mathrm{ZnO}, \mathrm{CuO}$ and $\mathrm{SiC}$, Wear, 258 (9): 1411-1421.

Bakunin, V. N.; Suslov, A. Y.; Kuzmina, G. N. and Parenago, O. P. (2004). Synthesis, Characterization and Anti-Wear Properties of CuO-ZnO Nano lubricant, Journal of Nano Research, 6: 273-284.

Baskar, S. and Sriram, G. (2014). Tribological behavior of journal bearing material under different lubricants, Tribology in Industry, 36 (2): 127-133.

Battez, A. H.; Gonzalez, R.; Felgueroso, D.; Fernandez, J. E.; Fernandez, M. R. and Garcia, M. A. (2007). Study of $\mathrm{TiO}_{2}$ nanoparticles as lubricant additive in twoaxial groove journal bearing, Wear, 263: 1568-1574.

Battez, A. H.; Viesca, J. L.; Gonzalez, R.; Blanco, D., Asedegbega, E. and Osorio, A. (2010).
Friction reduction properties of a $\mathrm{CuO}$ nanolubricant used as lubricant for a NiCrBSi coating. Wear, 268: 325-328.

Bhaumik, S.; Prabhu, S. and Singh, K. J. (2014). Analysis of tribological behavior of carbon nano-tube based industrial mineral gear oil 250 cSt viscosity. Advanced Tribology, 2014: $1-8$.

Bhaumik, S. and Pathak, S. D. (2015). Tribological properties of IF-MoS $\mathrm{S}_{2}$ nanoparticles as lubricant additive on cylinder liner and piston ring tribo-pair. Tribology in Industry, 37 (2): 196-203.

Ghaednia, H.; Jackson, R. L. and Khodadadi, J. M. (2015). Synthesis of $\mathrm{ZnO}$ nanograins by immersing $\mathrm{Zn}$ powders in oxalic acid solution plus thermal decomposition. Journal of Nanoscience, 10 (1): 1-18.

Jianhua, Q.; Yu, Z.; Lingling, W. and Jinjuan, X. (2011). Effects of $\mathrm{F}^{-}$Doping on the Photocatalytic Activity and Microstructures of Nanocrystalline $\mathrm{TiO}_{2}$ Powders. Petro Processing \& Petro chemical Technology, 13 (3): 69-73.

Paudel, S.; Dandeliya, S.; Chaurasiya, R.; Srivastava, A. and Kaphle, G. C. (2016). Magnetism in zigzag and armchair $\mathrm{CuO}$ nanotubes: Ab-initio study. Journal of Magnetism and Magnetic Materials, 406: 8-14.

Trajano, M. F.; Moura, E. I. F.; Ribeiro, K. S. B. and Alves, S. M. (2014). Utilization of vegetable oil as bio-lubricant and additive. Material Research, 17 (5): 1124-1128.

Wu, Y.; Tsuia, W. and Liu, T. (2007). Preparation and tribological properties of dual-coated $\mathrm{TiO}_{2}$ nanoparticles as water-based lubricant additives. Wear, 262: 819-825.

Zhou, J.; Yang, J.; Zhang, W.; Liu, W. and Xue, Q. (1999). Extended dislocation in physically deformed metallic nanoparticles. Material Research Bulletin, 34 (9): 1361-1367.

Zhou, Z.; Wu, Z.; Zhang, Z.; Liu, W. and Dang, H. (2001). Ultracrystalline diamond: Synthesis, properties and applications. Wear, 249 (5-6): 333-337. 